\title{
Perforation of Meckel's diverticulum in a very low birth weight neonate with severe pneumoperitoneum and review of literature
}

\author{
Yu-jiao Wang, Ting Wang, Shun-lin Xia, You-cheng Zhang, Wei-bing Chen, Bing Li \\ Department of Pediatric Surgery, Huai'an Women and Children's Hospital, Huai'an, Jiang Su, 223002, China. \\ E-mail: libinghafy@163.com or chenwbhafy@163.com \\ Received: 8th October 2017, Revised: 25th December 2017, Accepted: 5th January 2018
}

\begin{abstract}
SUMMARY: Wang YJ, Wang T, Xia SI, Zhang YC, Chen WB, Li B. Perforation of Meckel's diverticulum in a very low birth weight neonate with severe pneumoperitoneum and review of literature. Turk J Pediatr 2019; 61: 460-465.

Perforation is a rare complication of Meckel's diverticulum (MD), but it could be severe, even life-threatening for pediatric patients. There is a paucity of data on etiology of perforation, as well as clinical manifestations, management and prognosis in very low birth weight (VLBW) neonates with perforated MD. We report a rare case of spontaneously perforated MD in a VLBW neonate presenting with severe pneumoperitoneum. To our knowledge, this is one of the earliest reported VLBW cases with this rare complication. Furthermore, we review relevant publications and summarize major characteristics of all VLBW cases previously reported in order to provide some practical experience and interesting issues for pediatricians. Perforated MD should be kept in mind when VLBW neonates present with pneumoperitoneum.
\end{abstract}

Key words: Meckel's diverticulum; intestinal perforation; very low birth weight; neonates; pneumoperitoneum.

Meckel's diverticulum (MD) is a common congenital anomaly of the small intestine, and associated with incomplete obliteration of the vitelline duct. ${ }^{1}$ It is a true diverticulum consisting of all three layers of the normal bowel wall, and may contain ectopic tissues such as gastric, pancreatic, and duodenal mucosa. ${ }^{2-4}$ The majority of patients with MD are asymptomatic, and those who develop complications could present with various manifestations. According to previous studies, the peak incidence of complicated MD was observed to be in childhood. ${ }^{3,5}$ The diagnosis of MD in children is still challenging due to insufficient awareness, nonspecific symptoms, and the broad differential diagnosis. ${ }^{6}$

Perforation is a rare complication of MD, but it could be severe, even life-threatening for pediatric patients. ${ }^{7}$ There is a paucity of data on the etiology of perforation, as well as clinical manifestations, management and prognosis in very low birth weight (VLBW) patients. Herein, we report and illustrate a case of spontaneously perforated MD in a VLBW neonate with severe pneumoperitoneum managed by emergent surgery. Furthermore, we review relevant publications to provide some practical experience and insightful issues for pediatricians, particularly those who encounter similar cases.

\section{Case Report}

A male neonate was born at 27 weeks gestation to a 31-year-old mother with premature rupture of membrane by cesarean section. His birth weight was 1370 grams and the general condition was stable early after birth, without cyanosis or hypoxia. Apgar scores were seven at both 5 and 10 minutes. But he developed respiratory distress syndrome at 15 minutes. The patient was rapidly transferred to neonatal intensive care unit (NICU), and his condition 
improved after continuous positive airway pressure (CPAP) and surfactant treatment.

On the 24th hour of life, the bedside X-ray, which was initially aimed to confirm the position of venous catheters, revealed signs of free air in the peritoneum (Fig.1). Although distension of his abdomen was not remarkable, intestinal perforation was suspected. However, his parents refused surgical intervention. One hour later, his abdominal distension progressed, and plain radiograph of his abdomen demonstrated significant pneumoperitoneum with bowels gathering together (Fig. 2). On the 26th hour, the baby was taken to the operating room for emergent laparotomy immediately after his parents gave their written consent. When general anesthesia was utilized, he already had severe abdominal distension.

Upon entering the peritoneal cavity, a lot of gas came out. There were no signs of peritonitis, and we didn't observe intraperitoneal haemorrhage or exudate accumulation. After careful examination of the entire bowel, a perforated MD was discovered, measuring up to $1.5 \mathrm{~cm}$ within about $20 \mathrm{~cm}$ of the ileocecal valve (Fig. 3). The diverticulum and

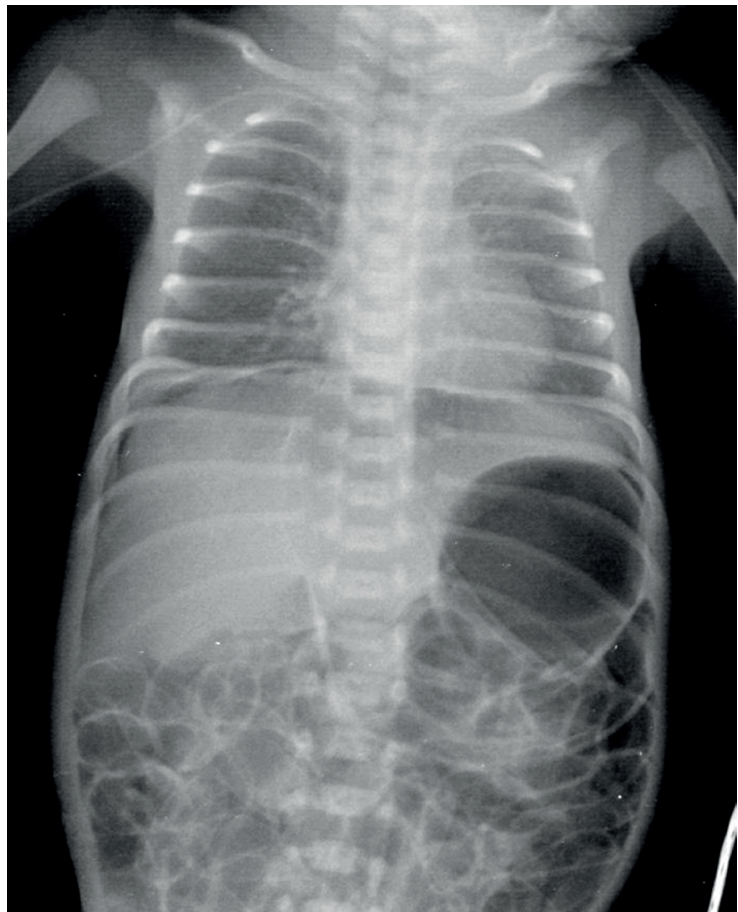

Fig. 1. Plain radiograph showing free gas on the 24th hour after birth.

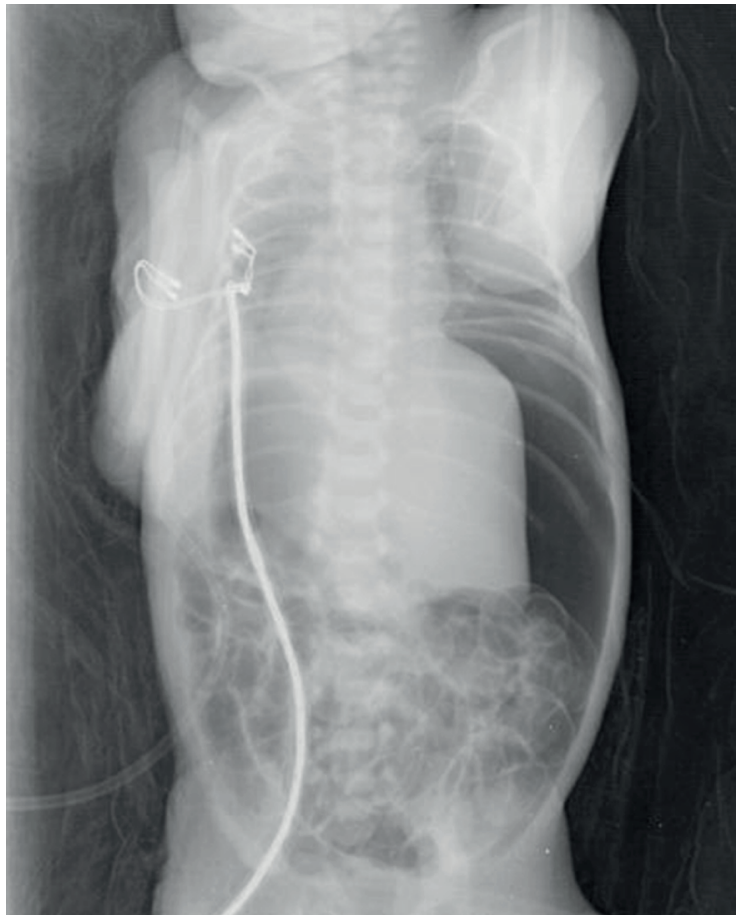

Fig. 2. Severe pneumoperitoneum accompanied with bowels gathering together was revealed by plain radiograph.

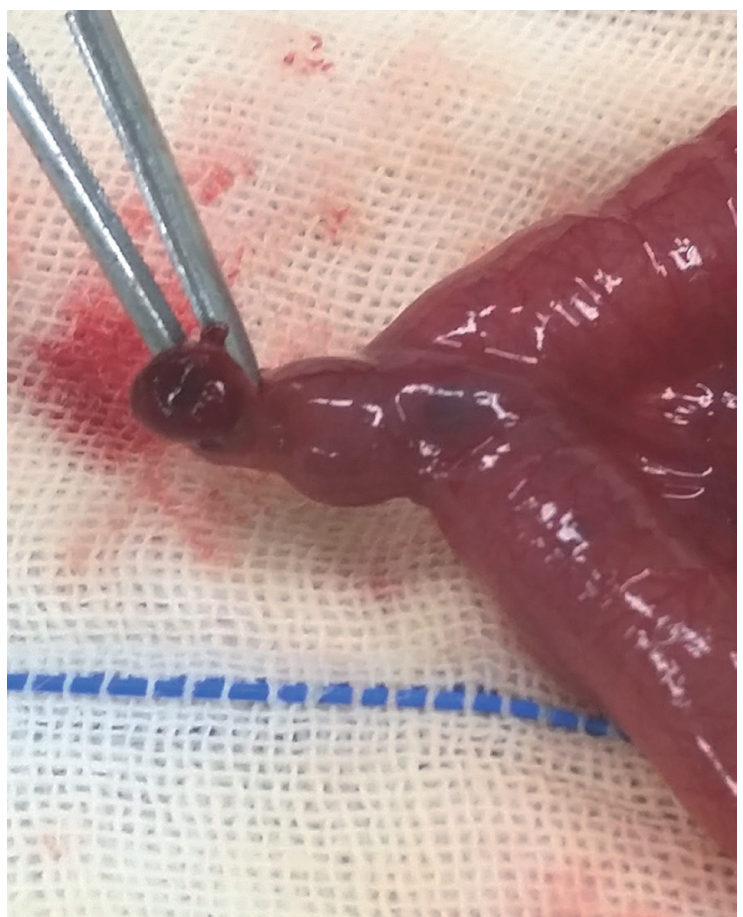

Fig. 3. Meckel's diverticulum with perforation at its tip. 
its surrounding bowel were macroscopically normal without involvement of inflammation. We didn't find any other suspected perforation area or other macroscopic pathology such as necrotising enterocolitis (NEC). Wedge bowel resection with transverse suturing was performed. Pathological examination confirmed the specimen was an MD with perforation, slightly focal infiltration of reactive inflammatory cells and no evidence of ectopic mucosa.

The patient recovered well from the surgery during the first 3 weeks. Recurrent abdominal distension and vomiting occurred approximately 2 weeks after enteral feeding was introduced. X-ray showed intestinal dilatation without signs of pneumoperitoneum. His symptoms improved quickly and significantly when enteral feeding was discontinued. The baby was discharged in stable condition well tolerating oral diet at the age of 57 days. Further follow-up is proceeding.

\section{Discussion}

Meckel's diverticulum could be found incidentally or when causing various complications. ${ }^{2}$ According to Cullen et $\mathrm{al}^{8}$, the lifetime risk of complications was estimated to be approximately $6.4 \%$. Although patients born with MD could develop complications at any age, the dominate types differ between children and adults. Pediatric patients tend to present with painless intestinal hemorrhage $e^{3,4,6}$, whereas diverticulitis and intestinal obstruction are more common in adult patients. ${ }^{4}$ Perforation is a rare complication of $\mathrm{MD}$, evident in approximately $3-10 \%$ of patients who have symptoms. ${ }^{5,6}$ To our knowledge, only four isolated cases of spontaneous MD perforation in VLBW neonates have been described in the literature ${ }^{7,9-11}$, information is summarized in Table I and II.

The mechanisms underlying the development of perforation of MD in VLBW neonates have not been fully elucidated. In adults and older children, perforation of MD is often secondary to mucosal ulceration caused by acid-producing ectopic tissue within the wall of MD. ${ }^{3,4}$ As observed in acute appendicitis, long, narrowbased diverticulum with poor self-emptying are more prone to luminal obstruction leading to subsequently inflammation, necrosis, and even perforation. ${ }^{12}$ According to previous studies, bowel obstruction was the most common presentation in term infants with perforated MD, which suggested that rupture of the thin diverticulum due to high pressure within lumen may play a vital role in the development of perforated MD in neonatal period. ${ }^{9,13}$ Of note, ectopic tissue appeared not to be the major cause of perforation of MD in VLBW neonates as displayed in Table I. ${ }^{7,9-11}$ Hypoxia, inadequate blood supply, permeability of the intestine, and early use of postnatal steroid and indomethacin are thought to increase the risk of spontaneous intestinal perforation (SIP), but the potential roles have not been

Table I. Clinical and Pathological Features of the Four Previous Isolated Cases of VLBW Neonates with Perforated MD.

\begin{tabular}{|c|c|c|c|c|c|c|c|}
\hline Reference & Sex & Gestation & Birth weight & Presentation & Age & $\begin{array}{l}\text { Presence } \\
\text { of ectopic } \\
\text { tissue }\end{array}$ & Pathology \\
\hline $\begin{array}{l}\text { Aguayo } \\
\text { et } \mathrm{al}^{9}\end{array}$ & Male & 28 weeks & $798 \mathrm{~g}$ & $\begin{array}{l}\text { abdominal distension, } \\
\text { pneumoperitoneum }\end{array}$ & 6 days & No & perforation \\
\hline $\begin{array}{l}\text { Smolkin } \\
\text { et } \mathrm{al}^{11}\end{array}$ & Male & 28 weeks & $1200 \mathrm{~g}$ & $\begin{array}{l}\text { abdominal distension, } \\
\text { pneumoperitoneum }\end{array}$ & 5 days & No & $\begin{array}{l}\text { perforation, } \\
\text { submucosal } \\
\text { hemorrhages }\end{array}$ \\
\hline $\begin{array}{l}\text { Khan } \\
\text { et } \mathrm{al}^{10}\end{array}$ & Male & 29 weeks & $650 \mathrm{~g}$ & $\begin{array}{l}\text { abdominal distension, } \\
\text { pneumoperitoneum }\end{array}$ & 6 days & NA & $\begin{array}{l}\text { perforation, } \\
\text { inflammation }\end{array}$ \\
\hline $\begin{array}{l}\text { Borgi } \\
\text { et } \mathrm{al}^{7}\end{array}$ & Male & 29 weeks & $1400 \mathrm{~g}$ & $\begin{array}{l}\text { abdominal distension, } \\
\text { pneumoperitoneum }\end{array}$ & 3 hours & No & $\begin{array}{l}\text { perforation, } \\
\text { discrete } \\
\text { inflammation }\end{array}$ \\
\hline
\end{tabular}

NA Not available 
Table II. Surgical Procedure and Clinical Outcome of the Four Previous Isolated Cases of VLBW Neonates with Perforated MD.

\begin{tabular}{|c|c|c|}
\hline Reference & Surgical procedure & Clinical Outcome \\
\hline Aguayo et $\mathrm{al}^{9}$ & $\begin{array}{l}\text { bowel segment resection and ileostomy; } \\
\text { reanastomosis was performed two months later }\end{array}$ & $\begin{array}{l}\text { had gastrointestinal dysfunction } \\
\text { related to prematurity and discharged } \\
\text { in stable condition }\end{array}$ \\
\hline Smolkin et $\mathrm{al}^{11}$ & $\begin{array}{l}\text { bowel segment resection with end-to-end } \\
\text { anastomosis }\end{array}$ & NA \\
\hline Khan et $\mathrm{al}^{10}$ & $\begin{array}{c}\text { bowel segment resection with end-to-end } \\
\text { anastomosis was performed when abdominal } \\
\text { distention occurred again after pulling out of draining } \\
\text { tube }\end{array}$ & $\begin{array}{l}\text { recovered well from surgery, but } \\
\text { demised following a suspected } \\
\text { aspiration episode }\end{array}$ \\
\hline Borgi et $\mathrm{al}^{7}$ & $\begin{array}{l}\text { bowel segment resection with end-to-end } \\
\text { anastomosis }\end{array}$ & $\begin{array}{l}\text { recovered well and discharged on day } \\
16 \text { of life }\end{array}$ \\
\hline
\end{tabular}

NA Not available

determined. ${ }^{14,15}$ It is yet to be investigated whether these factors predisposed MD to perforation in premature neonates. MD and the surrounding intestinal wall were involved with extensive inflammation in one of the four previous cases. It is unclear why the baby presented here developed a perforated MD. Both ectopic mucosa and gangrenous inflammation were absent pathologically. We infer that the perforation of MD may be mainly attributed to intestinal immaturity in this case.

Symptomatic MD has various clinical manifestations and is easily misdiagnosed preoperatively. ${ }^{6}$ Perforated MD often mimic acute complicated appendicitis with a sudden onset of peri-umbilical or right lower quadrant pain. ${ }^{16,17}$ Conventional radiographs have limited value in detecting perforated MD, and clinicians often don't have sufficient time to approach various diagnostic measures under the condition of acute abdomen. ${ }^{12}$ Although pneumoperitoneum is a vital radiological sign of the presence of intestinal perforation, it is often unremarkable when perforated MD occurs in adults and children. ${ }^{17-19}$ Conversely, pneumoperitoneum appears to be the most common symptom in VLBW neonates with perforated MD. ${ }^{7,9-11}$ We speculate that it may be associated with the use of noninvasive mechanical ventilation and fast conditions of these babies.

In neonates with intestinal perforation and abdominal distension, NEC is an important disease for differential diagnosis due to its similar clinical manifestations with SIP and other gastrointestinal disorders. ${ }^{20}$ NEC rarely occurs during the first week after birth. ${ }^{21}$ In comparison, SIP mainly affects infants of lower birth weight, more immaturity and at an earlier postnatal age. ${ }^{22}$ The median age of all the five VLBW cases with perforated MD at symptoms onset were 5 days (range: 3 hours to 6 days). Of note, intraoperative findings of the case we reported suggested that his severe abdominal distension appeared to be associated with the accumulation of free gas. Limited content of his peritoneal cavity could be a possible explanation, but mechanical ventilation may also partly contribute to the rapid progression of pneumoperitoneum. If the hypothesis did exist, it needs to be emphasized for clinicians to prohibit general condition of these patients form worsening and strive time for possibly delayed surgical intervention.

It is generally recommended that symptomatic MD should be removed and in some cases surgical intervention is urgent. ${ }^{8}$ Histological state of MD and the surrounding bowel and morphological characteristics are proposed to be taken into consideration when surgeons chose a surgical method., ${ }^{4,223}$ Complete resection of ectopic tissue is a vital step of the surgical procedure to minimize the risk of recurrent symptoms. ${ }^{24}$ Previous studies have provided evidence that the external appearance could indicate the distribution of ectopic mucosa within the wall of MD. ${ }^{23,25,26}$ Ectopic tissue were found to have a wide distribution 
from tip to base in short MD (HDR less than 1.6 or 2.0), and wedge resection of MD or segmental resection of the ileum containing the diverticulum was safer to avoid ectopic tissue being left. ${ }^{23,25}$ Transverse suturing is recommended to decrease the risk of narrowing the ileal lumen after wedge bowel resection. ${ }^{12}$

We performed wedge resection with transverse suturing for the baby presented here, considering the normal appearance of the surrounding bowel without signs of inflammatory involvement and shortening operative time.

The overall prognosis of SIP is better than perforation secondary to $\mathrm{NEC}^{27}$, but few studies focus on further intestinal problems after primary SIP. Drewett et al. ${ }^{28}$ found that neonates with SIP are at significant risk of further intestinal complications such as new spontaneous perforation and NEC. Indeed, these issues could occur as long as 3 months after the initial perforation and may require surgery. One death after suspected aspiration was reported in the four previous VLBW cases. ${ }^{10}$ The patient we reported was discharged in stable condition well tolerating oral diet. It is unclear whether his recurrent abdominal distension during hospitalization was attributed to his prematurity or surgery. Regular follow-up is necessary.

Perforated MD in VLBW neonates is very rare, but it should be kept in mind when these patients present with pneumoperitoneum in the neonatal period. The underlying mechanisms have not been fully elucidated and ectopic mucosa appeared to have little association with the development of perforation in VLBW neonates. Intestinal immaturity may be predominate in the case we reported, and the role of mechanical ventilation in the progress of abdominal distension needs to be further investigated. After prompt surgery, these patients could have a good clinical outcome, but long-period follow-up is needed with awareness of possible intestinal issues in their later life.

\section{REFERENCES}

1. Morris G, Kennedy A Jr, Cochran W. Small bowel congenital anomalies: A review and update. Curr Gastroenterol Rep 2016; 18: 16.

2. Choi SY, Hong SS, Park HJ, Lee HK, Shin HC, Choi GC. The many faces of Meckel's diverticulum and its complications. J Med Imaging Radiat Oncol 2017; 61: 225-231.

3. Chen JJ, Lee HC, Yeung CY, et al. Meckel's diverticulum: Factors associated with clinical manifestations. ISRN Gastroenterol 2014; 2014: 390869.

4. Rho JH, Kim JS, Kim SY, et al. Clinical features of symptomatic Meckel's diverticulum in children: Comparison of scintigraphic and non-scintigraphic diagnosis. Pediatr Gastroenterol Hepatol Nutr 2013; 16: 41-48.

5. Park JJ, Wolff BG, Tollefson MK, Walsh EE, Larson DR. Meckel diverticulum: The Mayo Clinic experience with 1476 patients (1950-2002). Ann Surg 2005; 241: 529-533.

6. Menezes M, Tareen F, Saeed A, Khan N, Puri P. Symptomatic Meckel's diverticulum in children: A 16-year review. Pediatr Surg Int 2008; 24: 575-577.

7. Borgi A, Bouziri A, Boujelbene N, Sghairoun N, Belhadj S, Benjeballah N. Perforated Meckel's diverticulum in a very preterm baby revealed at birth. Fetal Pediatr Pathol 2014; 33: 119-122.

8. Cullen JJ, Kelly KA, Moir CR, Hodge DO, Zinsmeister AR, Melton LJ 3rd. Surgical management of Meckel's diverticulum. An epidemiologic, population-based study. Ann Surg 1994; 220:564-568; discussion 568569.

9. Aguayo P, Fraser JD, St Peter SD, Ostlie DJ. Perforated Meckel's diverticulum in a micropremature infant and review of the literature. Pediatr Surg Int 2009; 25: 539-541.

10. Khan A, de Waal K. Pneumoperitoneum in a micropremie: Not always NEC. Case Rep Pediatr 2012; 2012: 295657.

11. Smolkin T, Hayari L, Zohar Y, Steinberg R, Makhoul IR. Meckel diverticulum in a premature infant: Too tiny but still perforates. J Pediatr 2013; 162: 1075.e1.

12. Ding Y, Zhou Y, Ji Z, Zhang J, Wang Q. Laparoscopic management of perforated Meckel's diverticulum in adults. Int J Med Sci 2012; 9: 243-247.

13. Frooghi $M$, Bahador A, Golchini A, Haghighat $M$, Ataollahi M, Javaherizadeh H. Perforated Meckel's diverticulum in a 3-day-old neonate; A case report. Middle East J Dig Dis 2016; 8: 323-326.

14. Tiwari C, Sandlas G, Jayaswal S, Shah H. Spontaneous intestinal perforation in neonates. J Neonatal Surg 2015; 4: 14.

15. Gordon PV. Understanding intestinal vulnerability to perforation in the extremely low birth weight infant. Pediatr Res 2009; 65: 138-144. 
16. Borowski DW, Hobday C, Agarwal AK. Haemoperitoneum caused by perforation of Meckel's diverticulum in a 5-year-old child. BMJ Case Rep 2010. doi: 10.1136/bcr.01.2010.2662.

17. Farah RH, Avala P, Khaiz D et al. Spontaneous perforation of Meckel's diverticulum: A case report and review of literature. Pan Afr Med J 2015; 20: 319.

18. Maclean W, Szentpali K. Large gallstone impaction at a Meckel's diverticulum causing perforation and localized peritonitis: Report of a case. J Surg Case Rep 2013. doi: $10.1093 /$ jscr/rjt097.

19. Raturi S, Chandran S, James TEH, Rajadurai VS. Radiological signs of pneumoperitoneum in an extremely low birthweight infant. BMJ Case Rep 2014; 2014: bcr2014205510.

20. Shah BA, Migliori A, Kurihara I, Sharma S, Lim YP, Padbury J. Blood level of inter-alpha inhibitor proteins distinguishes necrotizing enterocolitis from spontaneous intestinal perforation. J Pediatr 2017; 180: 135-140.e1.

21. Stout G, Lambert DK, Baer VL, et al. Necrotizing enterocolitis during the first week of life: A multicentered case-control and cohort comparison study. J Perinatol 2008; 28: 556-560.

22. Attridge JT, Clark R, Walker MW, Gordon PV. New insights into spontaneous intestinal perforation using a national data set: (1) SIP is associated with early indomethacin exposure. J Perinatol 2006; 26: 93-99.
23. Varcoe RL, Wong SW, Taylor CF, Newstead GL. Diverticulectomy is inadequate treatment for short Meckel's diverticulum with heterotopic mucosa. ANZ J Surg 2004; 74: 869-872.

24. Chan KWE, Lee KH, Wong HYV, et al. Laparoscopic excision of Meckel's diverticulum in children: What is the current evidence? World J Gastroenterol 2014; 20: $15158-15162$.

25. Mukai M, Takamatsu H, Noguchi H, Fukushige T, Tahara H, Kaji T. Does the external appearance of a Meckel's diverticulum assist in choice of the laparoscopic procedure? Pediatr Surg Int 2002; 18: 231-233.

26. Robijn J, Sebrechts E, Miserez M. Management of incidentally found Meckel's diverticulum a new approach: Resection based on a Risk Score. Acta Chir Belg 2006; 106: 467-470.

27. Fisher JG, Jones BA, Gutierrez IM, et al. Mortality associated with laparotomy-confirmed neonatal spontaneous intestinal perforation: A prospective 5-year multicenter analysis. J Pediatr Surg 2014; 49: 1215-1219.

28. Drewett MS, Burge DM. Recurrent neonatal gastrointestinal problems after spontaneous intestinal perforation. Pediatr Surg Int 2007; 23: 1081-1084. 